ARTICLE

\title{
Outpatient management of adult alcoholism
}

\author{
M F Williams, MB ChB, FCPsych (SA) \\ Department of Mental Health and Psychiatry, University of Cape Town, South Africa
}

Corresponding author: M F Williams (drmfwilliams@gmail.com)

S Afr Med J 2014;104(1):73. DOI:10.7196/SAMJ.7730

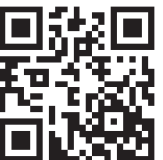

\section{Introduction and} epidemiology

Alcohol consumption is responsible for an estimated $3.8 \%$ of all deaths and $4.6 \%$ of disability-adjusted lifeyears (DALYs) globally. ${ }^{[1]}$

In $2000,7.1 \%$ of all deaths and $7.0 \%$ of total DALYs were attributable to alcohol. ${ }^{[2]}$ Alcohol remains South Africa's most abused substance. ${ }^{[3]}$ Fourteen per cent of the population are thought to receive lifetime diagnoses for alcohol abuse and/or dependence, ${ }^{[4]}$ while $28-39 \%$ of South African adults consume alcohol. ${ }^{[5]}$

This article outlines the outpatient management of adult alcoholism and emphasises a primary healthcare approach.

\section{Definitions}

- Alcoholism: Harmful drinking patterns that include alcohol abuse and dependence.

- Unit of alcohol:

- 1 unit $=10 \mathrm{ml}$ of alcohol.

- Number of units of alcohol in a drink = alcohol percentage/1 000 $\mathrm{x}$ volume of drink in millilitres. ${ }^{[6]}$

- Associate: Any person who is clinically relevant in the patient's life, e.g. a family member, friend, colleague, spiritual counsellor or community member.

- Healthcare professional (HCP): For the purposes of this paper the term includes doctors, psychologists, social workers, occupational therapists and registered nurses.

\section{Assessment and diagnosis \\ History taking}

It is important that all patients be explicitly asked about alcohol usage. Patients may minimise, rationalise or even frankly deny alcohol consumption. A collateral history from well-positioned associates is often necessary. ${ }^{[6,7]}$

\section{Taking a good alcohol history ${ }^{[8]}$}

Amounts and pattern of consumption

- Enquire about amounts, frequency and pattern (e.g. binging) of alcohol consumption.

- The type of alcohol consumed is also very important as the concentration varies across them.

- The units of alcohol may be calculated.

Associated behaviours

- Does the patient drink alone or in company?

- Triggers for and activities during intoxication

- How is the alcohol paid for?

- Are there violent behaviours directed towards others or themselves?

- Are there other types of risky behaviours while intoxicated, e.g. driving or unsafe sex?
Evidence of abuse

- Is there continued drinking despite negative consequences?

Evidence of dependence

- Are there signs of increased tolerance to alcohol?

- Are there any current symptoms (or previous history) of physiological withdrawal?

- Symptoms usually present 6 hours to 6 days after the last drink

- Symptoms occur on a background history of heavy, prolonged drinking.

- Symptoms include

- Headache, nausea, anxiety, agitation, confusion and, in severe cases, hallucinations.

- Is there compulsive drinking?

Consider medical and psychiatric comorbidities.

Consider previous interventions and treatments.

\section{Screening questionnaires}

The use of screening questionnaires is strongly recommended. ${ }^{[7,8}$

Alcohol use disorders identification test (AUDIT) (Table 1). This is currently the only instrument specifically designed to identify alcoholism and is valid for use in the general population. It is a 10-item questionnaire and each item is rated $0-4$. Scores above 19 point towards high levels of risk. A score of 8 - 19 for men and 7 - 19 for women suggest problematic drinking. ${ }^{[9]}$

CAGE questionnaire. This is a commonly used clinical screening tool. ${ }^{[6]}$ It may be administered to the patient or an associate.

- Has the patient had failed attempts to $c u t$ down?

- Do others get annoyed by their continued use of alcohol?

- Do they sometimes feel $g$ uilty by their inability to stop?

- Do they sometimes drink an early-morning eye opener/'Regmaker'?

\section{Physical examination}

Look out for:

Signs of intoxication.

Signs of withdrawal:

- Signs of autonomic over-activity.

- Tremor is common

- Sweating, agitation with increased blood pressure and pulse may be evident.

- Vomiting may be present.

- Seizures, confusion and hallucinations may be present in severe cases.

- Violence is also not uncommon. It should be averted in the early detection and prevention of these cases.

Medical comorbidities: Alcohol affects multiple organ systems directly, e.g. liver, central nervous system, gastrointestinal system, etc. It is also 
Table 1. Alcohol use disorders identification test (AUDIT) questions and scoring

\begin{tabular}{|c|c|c|c|c|c|}
\hline Questions & $\mathbf{0}$ & 1 & 2 & 3 & 4 \\
\hline 1. How often do you drink alcohol? & Never & Monthly or less & 2 - 4 times a month & 2 - 3 times a week & $\begin{array}{l}4 \text { or more times } \\
\text { a week }\end{array}$ \\
\hline $\begin{array}{l}\text { 2. How many standard drinks containing } \\
\text { alcohol do you have on a typical day when you } \\
\text { are drinking? }\end{array}$ & $1-2$ & $3-4$ & $5-6$ & $7-9$ & 10 or more \\
\hline $\begin{array}{l}\text { 3. How often do you have six or more standard } \\
\text { drinks on one occasion }\end{array}$ & Never & Less than monthly & Monthly & Weekly & $\begin{array}{l}\text { Daily or almost } \\
\text { daily }\end{array}$ \\
\hline $\begin{array}{l}\text { 4. How often during the last year have you } \\
\text { found that you were not able to stop drinking } \\
\text { once you had started? }\end{array}$ & Never & Less than monthly & Monthly & Weekly & $\begin{array}{l}\text { Daily or almost } \\
\text { daily }\end{array}$ \\
\hline $\begin{array}{l}\text { 5. How often during the last year have you } \\
\text { failed to do what was normally expected of you } \\
\text { because of drinking? }\end{array}$ & Never & Less than monthly & Monthly & Weekly & $\begin{array}{l}\text { Daily or almost } \\
\text { daily }\end{array}$ \\
\hline $\begin{array}{l}\text { 6. How often during the last year have you } \\
\text { needed a drink in the morning to get yourself } \\
\text { going after a heavy drinking session? }\end{array}$ & Never & Less than montly & Monthly & Weekly & $\begin{array}{l}\text { Daily or almost } \\
\text { daily }\end{array}$ \\
\hline $\begin{array}{l}\text { 7. How often during the last year have you had } \\
\text { a feeling of guilt or remorse after drinking? }\end{array}$ & Never & Less than monthly & Monthly & Weekly & $\begin{array}{l}\text { Daily or almost } \\
\text { daily }\end{array}$ \\
\hline $\begin{array}{l}\text { 8. How often during the last year have you } \\
\text { been unable to remember what happened the } \\
\text { night before because of your drinking? }\end{array}$ & Never & Less than monthly & Monthly & Weekly & $\begin{array}{l}\text { Daily or almost } \\
\text { daily }\end{array}$ \\
\hline $\begin{array}{l}\text { 9. Have you or someone else been injured } \\
\text { because of your drinking? }\end{array}$ & No & & $\begin{array}{l}\text { Yes, but not in the } \\
\text { last year }\end{array}$ & & $\begin{array}{l}\text { Yes, during the } \\
\text { last year }\end{array}$ \\
\hline $\begin{array}{l}\text { 10. Has a relative, friend, doctor or other } \\
\text { healthcare worker been concerned about your } \\
\text { drinking or suggested you cut down? }\end{array}$ & No & & $\begin{array}{l}\text { Yes, but not in the } \\
\text { last year }\end{array}$ & & $\begin{array}{l}\text { Yes, during the } \\
\text { last year }\end{array}$ \\
\hline
\end{tabular}

a risk factor for illnesses such as tuberculosis and HIV. ${ }^{[10]}$

Injuries: They are common and must also be looked for.

\section{Investigations}

Do liver function tests (LFTs) and a full blood count where possible. ${ }^{[8]}$ It may not be necessary to do a LFT but rather just aspartate aminotransferase (AST), alanine aminotransferase (ALT) and gamma-glutamyl transpeptidase (GGT). Other tests should be done as indicated.

\section{Treatment}

A comprehensive biopsychosocial approach is required. This may require co-operation between several healthcare professionals. Different aspects of treatment take priority at different times in the patient's care.

\section{When to refer to hospital ${ }^{[8]}$}

Severe current intoxication and poisoning

- Where there is respiratory or airway compromise.

- If methanol poisoning is suspected.

Depressed level of consciousness or acute confusion following severe alcohol consumption

If the following are present or suspected:

- Wernicke's encephalopathy (nystagmus, ataxia and ophthalmoplegia in severe cases)

- head injury
- alcohol withdrawal delirium (common causes of delirium need to be excluded).

Severe alcohol withdrawal is present or likely:

- a past history of severe withdrawal, delirium tremens or seizures

- benzodiazepine dependence

- rapid onset of severe withdrawal symptoms

- comorbid medical or psychiatric illnesses.

Psychiatric

Involuntary treatment required for:

- issues of safety, e.g. suicidality

- alcohol rehabilitation in severe alcoholism (social worker and court order required).

Psychiatric comorbidity requiring admission.

Medical

- Comorbidities and other conditions.

\section{Medical treatment}

Outpatient detoxification $^{[11]}$

Alcohol withdrawal carries significant morbidity and mortality when mismanaged. Mild to moderate alcohol withdrawal may be managed on an outpatient basis.

Benzodiazepines are the gold standard. Diazepam is widely used locally. It is generally given for 5 - 10 days. The dosage is titrated to 
need. Typical doses are 5-15 mg 2 - 3 times per day given orally. In cases of liver compromise, lorazepam may be considered as an alternative.

Daily thiamine (100 mg) and vitamin B complex (2 tablets) are primarily prescribed to prevent Wernicke-Korsakoff syndrome.

If the patient relapses, it is recommended that the detoxification be stopped.

Pregnant women experiencing alcohol withdrawal require a complex risk-benefit analysis as benzodiazepines are well-known teratogens. It is the author's opinion that a specialist be consulted at this stage.

\section{Relapse prevention ${ }^{[8,11]}$}

Relapse-preventing medications are best prescribed in conjunction with psychosocial interventions. They may significantly reduce alcoholism in some patients.

Please refer to standard pharmacological texts for more comprehensive information if necessary.

\section{Acamprosate}

Indication: Relapse prevention in alcohol-dependent patients. It has been found to have a modest treatment effect. Usually prescribed for 12 months.

Contraindicated: Severe hepatic or renal disease. Pregnancy or lactation.

Initiation: As soon as abstinent. Baseline LFT and urea and electrolytes (U\&E) essential before initiation of treatment.

Dosages: Adults weighing over $60 \mathrm{~kg}: 666 \mathrm{mg} 3$ times a day; adults weighing under $60 \mathrm{~kg}: 333 \mathrm{mg}$ twice a day.

Side-effects: Gastrointestinal upset, pruritus and other skin reactions. Generally well tolerated.

\section{Naltrexone}

Indication: Moderately to severely alcohol-dependent patients. Firstline agent. Suppresses the urge to drink.

Formulations: Oral and long-acting injectable.

Contraindicated: Acute liver failure.

Initiation: Physical examination and baseline U\&E and LFT before starting.

Dosages: Starting: $50 \mathrm{mg} /$ day; maintenance: 50 - $100 \mathrm{mg} /$ day.

Side-effects: Nausea (especially upon initiation), headache, abdominal pain. Reduced appetite and lethargy. Generally well tolerated.

Drug interactions: Co-prescription with opioid agonist analgesics to be avoided.

Caution: Hepatotoxicity possible at higher doses.

\section{Disulfiram (Antabuse)}

Indication: Relapse prevention in moderately to severely alcoholdependent patients. Weaker evidence than for naltrexone or acamprosate (NICE). Usually prescribed for 6 months.

Contraindicated: Cardiac failure, coronary artery disease, cerebrovascular disease, pregnancy, lactation, liver disease and peripheral neuropathy.

Initiation: Disulfiram leads to the accumulation of a toxic metabolite of alcohol, which leads to uncomfortable physical symptoms. It can only be initiated 24 hours after the last drink.

Dosages: $800 \mathrm{mg}$ for the first dose, reducing to $100-200 \mathrm{mg}$ daily. Side-effects: Halitosis is common

Cautions: Patients must be informed about the dangers of continued drinking while on disulfiram. These dangers include arrhythmias, hypotension and collapse.

\section{Psychosocial interventions}

Advice on safe drinking ${ }^{[6,11]}$

- $<14$ units/week for women and $<21$ units/week for men

- at least 2 alcohol-free days/week

- avoid binges

- never drink before or during any potentially dangerous activity (driving/swimming/operating heavy machinery)

- pregnancy

- advised not to drink at all (even small amounts may harm the baby)

- larger amounts may cause major complications, e.g. fetal alcohol syndrome

- pregnant women who insist on drinking

- advised not to drink during the first trimester

- 1 - 2 units of alcohol twice/week in second and third trimesters.

\section{Stages-of-change model}

Remission is possible at any point in the cycle, but generally comes after the maintenance phase (Fig. 1). It often requires active maintenance, as relapse is always a possibility.

The stages-of-change model was first described by Prochaska and DiClemente in 1986. It is a useful model to keep in mind when offering services to patients living with alcoholism. It suggests that patients move through various stages of motivation in the cycle of addiction.

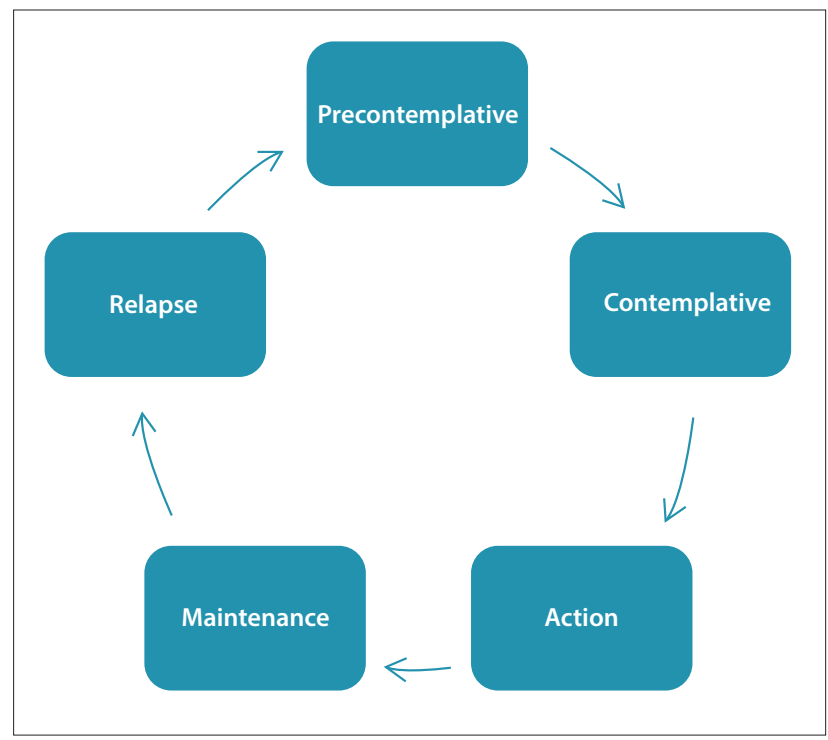

Fig. 1. Stages-of-change model.

\section{Motivational interviewing ${ }^{[6]}$}

This style of communication is useful and cuts across various types of psychotherapies. The key features of motivational interviewing are:

- Empathy. It is very important to establish rapport as soon as possible. A non-judgemental, empathic and open style is essential. This lends itself to honesty and a collaborative relationship between HCP and patient.

- Avoidance of arguments and managing resistance. The patient's resistance to change is likely to increase if the HCP adopts a critical, authoritarian or hostile stance. These patients may evoke strong negative emotions in the HCP. It is important for the HCP to manage these feelings. The HCP should try to communicate respect, hope and acceptance throughout the therapeutic process.

- Develop discrepancy. The HCP facilitates the patient's identification of ambivalent feelings and thoughts regarding their alcoholism. 
Once identified, behavioural changes and other strategies that are necessary to negate this ambivalence are explored. These strategies are generated by the patients themselves.

- Support self-efficacy. Providing hope is paramount. If patients become pessimistic, they will not believe that they can conquer their alcoholism. Positive affirmations and reinforcements from the HCP are vital.

\section{Brief (individual) interventions ${ }^{[6-8]}$}

This intervention involves short and regular meetings between patient and HCP. It is both cost and time efficient and indicated in low-to-moderate-risk alcoholism.

\section{Method}

Brief intervention focuses on three main approaches. First, providing information, e.g. pamphlets. Second, increasing the patient's motivation to change alcohol-abusing behaviours. Third, teaching and fostering positive behaviours.

There are several forms of brief interventions in the literature. One approach to delivery is best captured in the acronym FRAMES:

Feedback: This should be given regarding the risks and current negative effects of the patient's continued alcoholism.

Responsibility: The HCP non-judgementally emphasises the patient's responsibility for the problem.

Advice: Verbal and other forms of advice should be offered, e.g. pamphlets.

Мепи: Options regarding treatment, e.g. referral to psychotherapy.

Empathy: As per motivational interviewing.

Self-efficacy: As per motivational interviewing.

\section{System therapies}

There are several different system therapies found in the literature. Not all are suited to primary healthcare settings. It is essential to include family members and other associates wherever appropriate. Brief couples therapy is an example.

\section{Brief couples therapy $(\mathrm{BCT})^{[12]}$}

There exists a robust body of evidence for BCT. Patients who receive $\mathrm{BCT}$ enjoy more abstinence, fewer alcohol-related problems, and happier relationships than those who receive only individual treatments. This type of therapy is indicated where one member of the couple has a current alcohol problem, if they are married or have been living together for at least a year. Contraindications are current psychosis and domestic violence.

\section{Method}

BCT takes place during $15-20$ outpatient sessions over $5-6$ months. The HCP sees the couple together. A daily sobriety contract is drawn up in the session. In the contract, the patient agrees not to drink and the partner agrees to support these daily efforts. The partner may be contracted to witness the use of and adherence to prescribed relapse prevention medications. The partner is also responsible for documenting the daily performance on a calendar. This is reported at the next appointment. Any difficulties are not discussed at home but rather in session, to minimise domestic tensions. Assignments are designed to share activities and nurture positive communication styles and feelings.

\section{Social interventions}

Alcoholism has wide-reaching effects. It may be necessary to involve the services of a social worker. Issues around employment, family and legal difficulties, e.g. protection orders, are not uncommon. Self-help groups, e.g. Alcoholics Anonymous (AA), may also prove to be helpful. Spiritual, religious and other cultural factors may be of significance and must be explored and addressed when necessary.

\section{Summary}

- Adult alcoholism is a significant problem both locally and in many areas abroad.

- The effective treatment by HCPs of established alcoholism requires a comprehensive biopsychosocial approach.

- Proper clinical screening of all patients for alcoholism is essential.

- Issues of safety must always be considered in all patients.

- Inpatient treatment may be mandatory for medical or psychiatric reasons.

- Outpatient medical treatments include detoxification, vitamin supplementation and relapse prevention.

- Psychosocial interventions are aimed at the patient and associates wherever possible.

\section{Useful contacts}

Families South Africa (FAMSA): tel: (011) 975-7106/7; http://www. famsa.org.za

Alcoholics Anonymous (AA): 0861 HELP AA (435 722); http:// www.aasouthafrica.org.za

Acknowledgements: Professor C Lund for providing me with the Mental Health Gap Action Programme (mhGAP) Intervention Guide for Mental, Neurological and Substance Use Disorders in Non-Specialized Health Settings booklet.

\section{References}

1. Rehm J, Mathers C, Popova S, et al. Global burden of disease and injury and economic cost attributable to alcohol use and alcohol-use disorders. Lancet 2009;373(9682):2223-2233. [http:// dx.doi.org/10.1016/S0140-6736(09)60746-7]

2. Peltzer K, Davids A, Njuho P. Alcohol use and problem drinking in South Africa: Findings from a national population-based survey. African Journal of Psychiatry 2011;14:30-37.

3. Pasche S, Myers B. Substance misuse trends in South Africa. Human Psychopharmacology Clinical Experience 2012;27:338-341. [http://dx.doi.org/10.1002/hup.2228]

4. Herman AA, Stein DJ, Seedat S, et al. The South African Stress and Health (SASH) study: 12-month 4. Herman AA, Stein DJ, Seedat S, et al. The South African Stress and Health (SASH) stude
and lifetime prevalence of common mental disorders. S Afr Med J 2009;99:339-344.

5. Department of Health. Medical Research Council of South Africa. Demographic and Health Survey 2003. Department of Health: Pretoria, 2007.

2003. Department of Health: Pretoria, 2007.
6. Weich L. Alcohol and other substance-use disorders. In: Baumann SE. ed. Primary Health Care 6. Weich L. Alcohol and other substance-use disorders. In: Baumann SE. ed. Primary
Psychiatry: A Practical Guide for Southern Africa. Cape Town: Kenwyn Juta, 2007.

7. Babor TF, McRee BG, Kassebaum PA, et al. Screening, Brief Intervention, and Referral to Treatment (SBIRT): Toward a public health approach to the management of substance abuse. Focus 2011;9:130-148.

8. World Health Organization. Mental Health Gap Action Programme (mhGAP) Intervention Guide for Mental, Neurological and Substance Use Disorders in Non-Specialized Health Settings. Geneva: WHO, 2010:86-94

9. Pengpid S, Peltzer K, Skaal L, et al. Screening and brief intervention for alcohol problems in Dr George Mukhari Hospital outpatients in Gauteng, South Africa: A single blinded randomized controlled trial protocol. BMC Public Health 2012;12:1-6. [http://dx.doi.org/10.1186/1471-2458-12-127]

10. Peltzer K, Naidoo P, Louw J, et al. Screening and brief interventions for hazardous and harmful alcohol use among patients with active tuberculosis attending primary public care clinics in South Africa: Results from a cluster randomized controlled trial. BMC Public Health 2013;13:699. [http:// Africa: Results from a cluster randomiz

dx.doi.org/10.1186/1471-2458-13-699]
11. Taylor D, Paton C, Kapur S. The Maudsley Prescribing Guidelines in Psychiatry. 11th ed. London: Wiley-Blackwell, 2012: Ch. 6.

Wiley-Blackwell, 2012: Ch. 6 .
12. O'Farrell TJ, Fals-Stewart W. Behavioral couples therapy for alcoholism and drug abuse. Journal of Substance Abuse Treatment 2000;18:51-54. [http://dx.doi.org/10.1016/S0740-5472(99)00026-4]

\section{Further reading}

- Patterson DA, Nochaski TH. Combining the Transtheoretical Stages of Change Model and the 12 Steps of Alcoholics Anonymous to Monitor Treatment Progression. Journal of Social Work Practice in the Addictions 2010;10:224-227. [http://dx.doi.org/10.1080/15332561003730262]

- University of Cape Town Primary Care 101 Integrated Guideline/Onsite Training, 2011/2012. Cape Town: Department of Health, Provincial Government of the Western Cape, 2012 